\title{
Inovasi Perguruan Tinggi Raharja Dalam Era Disruptif Menggunakan Metodologi iLearning
}

\author{
Untung Rahardja ${ }^{1}$,Ninda Lutfiani ${ }^{2}$, Arini Dwi Lestari ${ }^{3}$, Edward Boris P Manurung ${ }^{4}$ \\ ${ }^{1,2,3}$ STMIK Raharja Tangerang, ${ }^{4}$ Swiss German University \\ 1'untung@ raharja.info, ${ }^{2}$ ninda@ $\mathrm{raharja.info,}{ }^{3}$ arini.dwi@ raharja.info, ${ }^{4}$ edward@ aptisi.or.id
}

\begin{abstract}
ABSTRAK. Perkembangan teknologi yang sedemikian pesat berdampak lahirnya era disruptif yaitu teori inovasi yang dicetuskan oleh newcumbent yang keberadaannya megancam incumbent. Efek dari Disruptif ini menyebabkan terjadinya perubahan yang signifikan secara mendasar dan meluasnya inovasi teknologi yang mengubah cara berhubungan antarmanusia dalam segala bidah tidak terkecuali pendidikan tinggi. Jika dilihat dari segi kuantitatif, pertumbuhannya cukup mengagumkan. Namun, bila di sangkutpautkan dengan mutunya, perkembangannya mencemaskan. Maka dari itu, pendidikan tinggi harus berlomba-lomba untuk mengubah sistem pembelajaran dengan mengikuti pola inovasi disruptif agar meningkatkan mutu pembelajaran yang akan berdampak terhadap peningkatan kualitas SDM (Sumber Daya Manusia). Dalam penelitian ini terdapat 2 (dua) metode yang digunakan, Hasil penelitian ini menyajikan kesiapan Perguruan Tinggi Raharja dalam menghadapi era disruptif melalui metodologi iLearning. Dimana dalam proses pembelajarannya meliputi 3 (tiga) hal, yaitu Rinfo, iDu dan iMe. Dengan metode pembelajaran ini, mahasiswa menjadi lebih inovatif dan kritis dalam berfikir.
\end{abstract}

Kata kunci : Era Digital, Inovasi Disruptif, iLearning

ABSTRACT. Rapidly technological advancements have led to the emergence of a disruptive era, namely the innovation theory that was initiated by newcumbent, the publication of which threatened incumbent. The effect of this disruptive is a fundamentally significant and widespread technological innovation that changes the way human relations in various heresies is no exception to higher education. When viewed from a quantitative perspective, the growth is quite severe. However, if it is related to its quality, its development is worrying. Therefore, higher education must compete to change the learning system by following disruptive patterns in order to improve the quality of learning that will improve the quality of human resources. In this study there are 2 (two) methods, The results of this study present the readiness of Raharja University in the face of the disruptive era through iLearning. Where in the learning process includes 3 (three) things, called Rinfo, iDu and iMe.With this learning method, students become more innovative and critical thinking.

Keywords : Era Digital, Disruptif Inovation, iLearning

\section{PENDAHULUAN}

Disruptif adalah teori dari inovasi yang digagas oleh pelaku dunia industri baru yang keberadaanya mengancam pelaku industri lama. Dengan kata lain, dengan adanya inovasi disruptif akan mendatangkan segala perubahan yang signifikan dalam segala bidang, tidak terkecuali dalam bidang pendidikan, khususnya pendidikan tinggi. Selain tidak pasti, kedatangannya pun tidak bisa terelakkan oleh siapapun. Perubahan disruptif dalam pendidikan ini terjadi karena cara mengajar yang telah berubah yang awalnya terpusat pada dosen menjadi terpusat pada siswa. Dengan demikian, cara siswa mencari informasi pun tidak hanya bergantung kepada dosen melainkan memanfaatkan perkembangan teknologi yang memungkinkan mahasiswa tersebut dapat melewati batas fisik ruang kuliah, kampus, kota bahkan negara.

Sementara itu, negara Indonesia mempunyai ambisi yang tinggi untuk dapat mengikuti perkembangan dunia, ikut serta menciptakan karya dunia, menikmati bonus demografi dan keluar dari jebakan negara dengan pendapatan menengah. Karena selama ini negara maju yang menjadi pusat perkembangan ilmu pengetahuan dan teknologi, menghadapi perubahan dengan arus yang cukup deras yang tak terbendung dan tidak mudah untuk diatasi dengan instrumen yang ada hari ini (Barber, Donelly dan Rizvi, 2013).

Hal ini sejalan dengan UUD 1945 Pasal 31 Bab XIII bahwa pemerintah mengusahakan dan menyelenggarakan suatu sistem pendidikan nasional dalam rangka mencerdaskan kehidupan bangsa yang diatur dalam UUD 1945, p.31. Berdasarkan Undang-Undang Sistem Pendidikan Nasional Nomor 20 Tahun 2003 Pasal 3 bahwa pendidikan nasional berfungsi mengembangkan kemampuan dan membentuk watak serta peradaban bangsa yang bermartabat dalam rangka mencerdaskan kehidupan bangsa, bertujuan untuk berkembangnya potensi peserta didik agar menjadi manusia yang beriman dan bertakwa kepada Tuhan Yang Maha Esa, berakhlak mulia, sehat, berilmu, cakap, kreatif, mandiri, dan menjadi warga negara yang demokratis serta bertanggungjawab. 
Manusia Indonesia dituntut untuk mampu berfikir kritis, menjadi pribadi yang lebih adaptif dalam upaya mencari solusi dari setiap permasalahan. Karena, diprediksikan sistem pendidikan tinggi Indonesia pasti akan menuju kepada perubahan disruptif, memutarbalikkan sistem yang sudah ada sampai akhirnya terjadi perubahan yang mendasar dalam keseluruhan sistem pendidikan Indonesia. Oleh sebab itu, Indonesia harus sesegera mungkin menyempurnakan sistem pendidikan tinggi untuk menyambut tantangan zaman.

Namun di Indonesia sendiri proses belajar mengajar masih berpusat pada dosen , sedangkan pada era disruptif ini proses belajar mengajar harus berpusat kepada mahasiswa. Dengan kata lain, dosen hanya sebagai fasilitator. Dan tantangan lain yang terkait digital disruptif, yaitu pembelajaran online, Pendidikan Tinggi harus sigap untuk menghadapi era disruptif. Agar dapat bersaing dengan kata lain tidak punah tergerus oleh era disruptif.

Hasil yang diharapkan dari analisis contoh inovasi iLearning dalam Era Disruptif ini adalah memberikan rekomendasi dalam hal penyempurnaan dan evaluasi dari inovasi iLearning. Kemudian hasil rekomendasi tersebut dapat diimplementasikan oleh Perguruan Tinggi Raharja yang menggunakan metodologi iLearning dalam kegiatan pembelajaran.

\section{METODE}

Metode penelitian adalah gambaran atau rencana dari sebuah kegiatan yang diteliti yang disusun secara sistematis dengan tujuan agar suatu penelitian dapat terealisasi.

Untuk mendukung penelitian ini, penulis telah menyertakan beberapa teori pendukung yang sejalan, diantaranya:

\subsection{Landasan teori}

\subsubsection{Disruptif}

Disruptif merupakan suatu inovasi berupa teknologi yang mampu menggancam keberadaan pasar yang sudah ada akibat terciptanya pasar baru dan pada akhirnya akan menggantikan pasar lama atau teknologi yang lama.Inovasi disruptif ini dapat naik daun dalam mengembangkan produk atau suatu layanan dengan cara yang tak terduga, biasanya dengan menciptakan jenis konsumen yang berbeda pada pasar yang baru dan menurunkan harga pada pasar yang lama (Clayton M Christensen (2016).

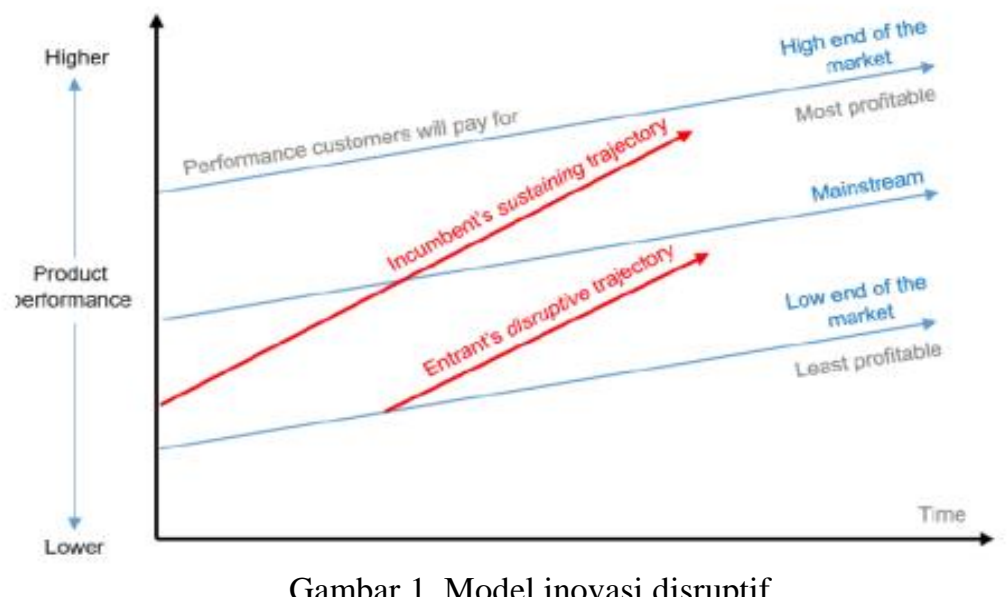

Gambar 1. Model inovasi disruptif

Sumber: (Latin American and Caribbean Competition Forum,2016 hal5)

Dalam Gambar 1. Dijelaskan bergaris biru merupakan pasar lama dan yang bergaris merah merupakan pesaing baru yang akan mengancam keberlangsungan pasar lama. Didalam teori persaingan pasar, dikenal dengan sebutan structure, conduct, and performance (SCP). Dengan adanya pesaing baru, struktur pasar akan berubah step by step. Diawali dengan konsumen yang sedikit demi sedikit bergeser kepada produk / jasa dengan harga jauh lebih rendah. Lalu,Conduct dipengaruhi oleh konsumen yang mengerti teknologi dan memanfaatkan teknologi tersebut sebagai jalan pintas untuk berbelanja. Dan yang terakhir performance, yaitu pasar baru tersebut menyesuaikan titik keseimbangan. Inovasi disruptif muncul bukan tanpa alasan. Inovasi disruptif muncul sebagai jawaban atas perkembangan teknologi terbaru yang 
ada pada era digital ini. Dengan kata lain, perkembangan pasar nantinya mengharuskan SCP dalam industri untuk berevolusi demi memenuhi kebutuhan konsumen sesuai dengan arus modernisasi saat ini.

Scott Anthony menyatakan pendapat yang hampir sama, dia mengungkapkan bahwa isu yang sedang naik daun saat ini ialah mengenai inovasi, karena dengan inovasi dapat mengubah tatanan baik dalam perusahaan maupun pasar. Untuk lebih jelas, dibawah ini ada beberapa contoh inovasi disruptif, antara lain:

1. Ensiklopedia cetak, pasar terdisrupsi oleh inovasi Wikipedia

2. Telegraf terdisrupsi oleh Telepon

3. Floppy Disk terdisrupsi oleh inovasi CD dan USB CD \& DVD

Sedangkan untuk perkembangan bisnis modern, contoh inovasi disruptif yang sedang terjadi, antara lain:

1. Perusahaan taksi terbesar di dunia (Uber) tidak memiliki taksi

2. Penyedia akomodasi terbesar di dunia (Airbnb) tidak memiliki real estate

3. Penyedia jasa transportasi Gojek tidak memiliki armada kendaraan namun valuasi Gojek melebihi valuasi Garuda Indonesia yang memiliki armada pesawat terbesar di Indonesia.

Setinggi apapun suatu perusahaan jika tidak mengikuti perkembangan zaman, akan terancam oleh perusahaan kecil yang fleksibel di era disruptif ini. Yang berakibat dapat mengubah bahkan menggantikan tatanan bisnis yang menawarkan solusi dengan biaya rendah.

\subsection{2 iLearning}

iLearning merupakan metodologi pembelajaran modern yang mengintegrasikan perpaduan antara belajar, bermain, berdoa dan bekerja. Dengan dipadukan unsur 4B tersebut, fungsi otak kanan dan otak kiri bekerja bersinergi (Dr. Ir. Untung Rahardja,M.T.I.,MM). Dalam metode pembelajaran iLearning ini membutuhkan media pendukung sebagai jembatan antara dosen dan mahasiswa dalam penyampaian materi bahan ajar perkuliahan.

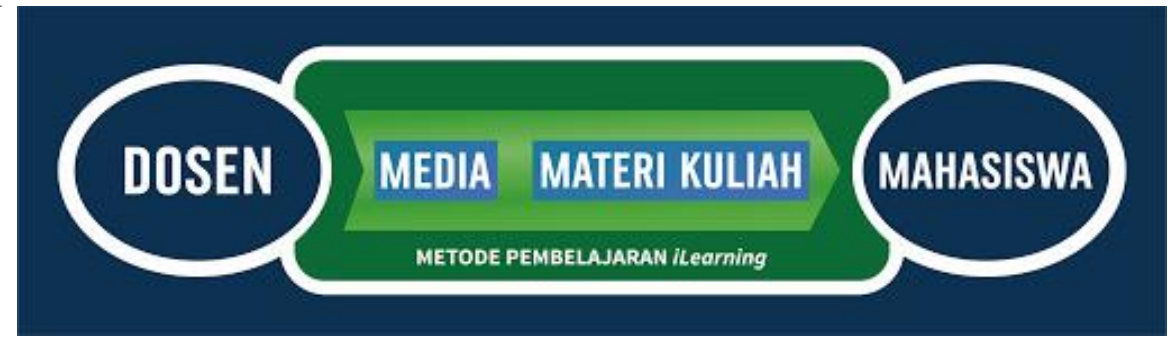

Gambar 2. Framework pembelajaran iLearning

Pada Gambar 2. Framework pembelajaran iLearning terdapat 2 aktor yang berperan dalam hal ini yaitu dosen dan mahasiswa. Yang mana Dosen dalam menyampaikan materi kuliah ke mahasiswa dan sebaliknya mahasiswa mengerjakan tugas yang diberikan oleh dosen menggunakan suatu media komunikasi yaitu iPad. Dikarenakan dalam proses pembelajaran, peran media informasi memiliki peran yang sangat penting (Arsyad, 2011). Dengan adanya iLearning, mahasiswa tidak harus membawa alat tulis ataupun sejenisnya karena semua itu dapat dilakukan di iPad. Dan tentunya membuat mahasiwa memiliki ketertarikan yang tinggi dalam menuntut ilmu. Penyampaian materi pun interaktif dan tidak membuat mahasiswa merasa jenuh. Apabila mahasiswa mempunyai respon yang baik, mahasiswa senantiasa bersifat aktif dalam mengikuti mata kuliah, maka akan terjalin interaksi yang baik antara dosen dengan mahasiswa selain itu akan mudah untuk menghidupkan pembelajaran yang efektif dan efisien di dalam kelas tersebut.

\section{Studi Literatur}

Studi literatur merupakan bahan atau materi yang tertulis dapat berupa buku atau jurnal yang terdapat pembahasan mengenai topik yang akan diteliti (Hermanawan, 2009).

Inovasi dalam menghadapi era disruptif dalam dunia pendidikan sebelumnya sudah ada. Literatur ini di tulis guna menghindari kesamaan dan mengindari pengulangan serta meneruskan penelitian yang sebelumnya pernah dilakukan. Terdapat 5 studi literatur yang memiliki relasi yang searah dengan penelitian ini, diantaranya :

1. Penelitian yang dilakukan oleh Jonathan Rossing, Willie M.Miller, Amanda K. Cecil dan Suzan E. Stamper berjudul "iLearning: The future of higher education? Student perception on learning with mobile tablets" dari Indiana University yang ditulis pada tahun 2012. Penelitian ini menyatakan bahwa iLearning dalam versi jurnal tersebut hanya sebatas Learning with iPad atau pembelajaran menggunakan iPad (Rossing, 2012). 
2. Penelitian yang dilakukan oleh Colin Beard, John P. Wilson, Richard McCarter yang berasal dari Sheffield Hallan University dengan judul "Towards a Theory iLearning : Experiential iLearning"yang ditulis pada tahun 2007. Metode penelitian dalam jurnal ini menggunakan studi kasus yang menggunakan model dari pengembangan teori pembelajaran mengggunakan CD-Rom. Materi bahan ajar yang disiapkan dalam konten video yang telah berbasis handout induksi. Dalam penelitian ini memadukan experiental learning (pengalaman belajar) dengan iLearning (interaksi elektronik)(Beard,2007).

3. Penelitian yang dilakukan oleh Minjuan Wang. Sean Hauze, William Olmstead, dan Breshna Aziz dengan judul “An Exploration of Intelligent Learning (iLearning) systems” yang ditulis pada tahun 2014. Jurnal ini membahas bahwa iLearning berasal dari inisiatif Ilnetlligent Campus (iCampus). iLearning dalam jurnal ini merupakan salah satu pilar dari 6 sistem pilar iCampus yang terdiri dari iLearning, iGovernance, iGreen, iHealth, iSocial dan iManagement sebagai kerangka kerja untuk memperkaya pembelajaran siswa (Wang, 2014).

4. Penelitian yang dilakukan oleh Rano kurniawan, Hender, Fitria Nursetianingsih berjudul "Penggunaan iPad Mendukung Pembelajaran pada Mahasiswa iLearning" yang ditulis pada tahun 2014. Penelitian ini membahas dengan adanya sarana iPad hal ini dapat memudahkan pembelajaran iLearning dan menciptakan integritas yang baik untuk proses pembelajaran. Mahasiswa dapat menjelajah berbagai hal, dimanapun, kapanpun selalu belajar dan selalu merasa senang, sehingga tercipta jiwa "iLearning" dan ilmu pengetahuan dapat diserap secara efektif dan efisien (Kurniawan, 2012).

5. Penelitian yang dilakukan oleh David Comiskey, Kenny McCartan pada tahun 2013 dengan judul "From Elearning to iLearning" dari University of Ulster, Irlandia Utara. Penelitian ini menjelaskna bahwa teknologi pengajaran dengan iLearning lebih menjanjikan daripada eLearning, karena siswa lebih memberikan feedback dari penggunaan PowerPoint sebagai metode mengajar. Selain itu, penggunaan aplikasi yang berkaitan dengan arsitektur telah mencapai keberhasilan yang tidak terduga, para siswa menemukan metode ini lebih bermanfaat dalam memahami elemen-elemen rumit yang detail (Comiskey, 2013).

\section{HASIL DAN PEMBAHASAN}

\subsection{Analisa Permasalahan}

Pada bagian analisa permasalahan in, penulis melakukan analisa dengan menggunakan Analisa SWOT, yaitu suatu langkah sistematis yang memiliki tujuan untuk mengindentifikasi faktor-faktor yang menentukan keberhasilan internal, meliputi : kekuatan dan kelemahan dan eksternal, meliputi : peluang dan ancaman (Blocher, 2007).

Pendapat lain menyatakan, analisa SWOT merupakan strategi perencanaan yang penting untuk membandingkan faktor internal, yaitu : kekuatan dan kelemahan serta eksternal, yaitu peluang dan ancaman (Wanti, 2014).

Perumusan analisa SWOT berdasarkan fakta yang ada antara fakta internal dengan situasi eksternal. Kesesuaian yang baik akan membuahkan dampak positif dari kekuatan dan peluang perusahaan serta meminimalisir kelemahan dan ancaman yang akan terjadi.

\begin{tabular}{|c|c|c|}
\hline & Strength (Kekuatan) & Weakness (Kelemahan) \\
\hline $\begin{array}{l}\text { Faktor } \\
\text { Eksternal }\end{array}$ & $\begin{array}{l}\text { 1. Fleksibel dalam kegiatan } \\
\text { pembelajaran (dilakukan kapan } \\
\text { saja dan dimana saja) } \\
\text { 2. Bebas mengulang } \\
\text { pembelajaran kapanpun dan } \\
\text { dimanapun }\end{array}$ & $\begin{array}{l}\text { 1. Bergantung kepada jaringan } \\
\text { internet } \\
\text { 2. Device sewaktu-waktu bisa } \\
\text { error/rusak }\end{array}$ \\
\hline Oportunity (Peluang) & Strategy $\mathrm{SO}$ & Strategy WO \\
\hline $\begin{array}{l}\text { Persaingan yang sehat } \\
\text { antar Perguruan Tinggi } \\
\text { dalam menghadapi era } \\
\text { disruptif }\end{array}$ & $\begin{array}{l}\text { Meningkatkan semangat } \\
\text { mahasiswa untuk pembelajaran } \\
\text { yang menyenangkan }\end{array}$ & $\begin{array}{l}\text { Mahasiswa diberi kebebasan } \\
\text { dalam memilih waktu dalam } \\
\text { mengerjakan tugas }\end{array}$ \\
\hline Threath (Ancaman) & Strategy ST & Strategy WT \\
\hline $\begin{array}{l}\text { Perguruan Tinggi luar } \\
\text { memiliki inovasi yang lebih } \\
\text { unggul dalam menghadapi } \\
\text { era disruptif }\end{array}$ & $\begin{array}{l}\text { Meningkatkan eksistensi } \\
\text { Perguruan Tinggi yang } \\
\text { menyelenggarakan iLearning }\end{array}$ & $\begin{array}{l}\text { Kebocoran data pribadi baik } \\
\text { dosen maupun mahasiswa }\end{array}$ \\
\hline
\end{tabular}

Gambar 4. Analisa SWOT Metodologi iLearning 
Pada gambar 4. terdapat analisa SWOT setelah diidentifikasi faktor internal dan eksternal yang meliputi Strength (Kekuatan), Weakness (Kelemahan), Opportunity (Peluang) dan Threath (Ancaman). Maka dapat disimpulkan oleh peneliti yaitu dirumuskan strategi SO berdasarkan perbandingan antara strength (kekuatan) dengan opportunity (peluang) adalah meningkatkan semangat mahasiswa dalam proses pembelajaran yang menyenangkan. Strategi ST diterapkan dalam perbandingan antara strength (kekuatan) dan thread (ancaman) adalah meningkatkan eksistensi Perguruan Tinggi yang menyelenggarakan iLearning karena tidak dapat dipungkiri bahwa mahasiswa saat ini memilih Perguruan Tinggi salah satu faktornya ialah kecanggihan teknologi yang ada pada Perguruan Tinggi tersebut. Strategi WO dapat diterapkan berdasarkan perbandingan antara weakness (kelemahan) dan opportunity (peluang) adalah mahasiswa diberikan kebebasan untuk mengerjakan tugas dalam waktu yang telah ditentukan. Strategi WT Weakness (Kelemahan) dan Threat (Ancaman) yang merupakan kemungkinan negatif yang terjadi adalah kebocoran data pribadi baik milik dosen maupun mahasiswa.

\subsection{Flowchart Algoritma}

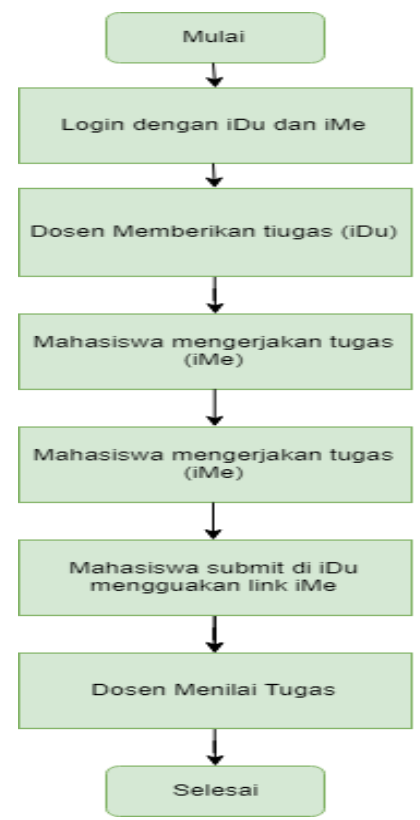

Gambar 3. Flowchart Rancangan Pembelajaran

Pada Gambar 3. menunjukan 5 (lima) langkah dalam metodologi iLearning, antara Rinfo, iDu dan iMe saling terintegrasi. Dijelaskan sebagai berikut: 1) Mahasiswa dan Dosen Login pada website iDu dan iMe menggunakan email Rinfo.2) Dosen membuat dan memberikan tugas di iDu.3) Mahasiswa mengerjakan tugas di IMe dengan cara add new post, publish dan di copy link tersebut. 4) Mahasiswa kembali ke iDu untuk submit tugas dengan link iMe yang sudah di copy. 5) Dosen menilai tugas yang telah dikerjakan mahasiswa di iDu.

\subsection{Peta Konsep}

Peta Konsep atau biasa disebut juga dengan Framework, ialah metode mengembangkan berbagai pikiran dan pandangan ke segala arah. Menangkap pola pikir yang berbeda-beda dari berbagai sudut. Framework juga dianggap sebagai metode mengembangkan cara berpikir yang berbeda atau divergen dan kreatif (Aini, 2017). Bertujuan sebagai pola berpikir yang sangat bijak serta merupakan cara yang paling efektif untuk menempatkan informasi ke dalam otak dan mengambil kembali informasi tersebut ketika kita membutuhkan(Rahardja,2016). 


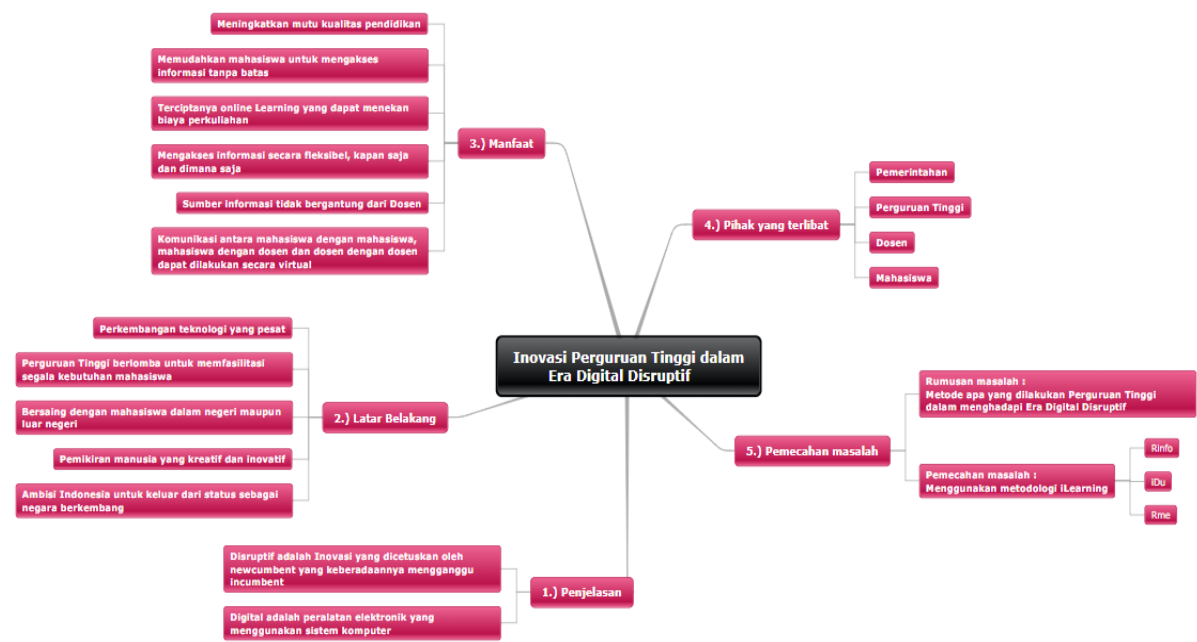

Gambar 5. Peta Konsep Metodologi iLearning

Framework Inovasi Perguruan Tinggi dalam menghadapi Era Digital Disruptif diatas terdiri dari : 1.) Penjelasan: Disruptif adalah inovasi yang dicetuskan oleh newcumbent yang keberadaanya mengganggu incumbent (CM Cristensen,2013) dan digital adalah peralatan elektronik yang menggunakan sistem komputer. 2.) Latar belakang: Inovasi disruptif ini dilatarbelakangi oleh perkembangan teknologi yang pesat, Perguruan Tinggi yang saling berlomba untuk memfasilitasi segala kebutuhan mahasiswa, persaingan antar mahasiswa dalam negeri maupun luar negeri, Pemikiran manusia yang semakin kreatif dan inovatif, dan ambisi Indonesia untuk keluar dari status sebagai negara berkembang. 3.) Manfaat: Meningkatkan mutu kualitas pendidikan, memudahkan mahasiswa untuk mengakses informasi tanpa batas, terciptanya online Learning yang menekan biaya perkuliahan, Mengakses informasi secara fleksibel kapan saja dan dimana saja, sumber informasi tidak bergantung dari Dosen, dan komunikasi antara mahasiswa dengan mahasiswa, mahasiswa dengan dosen maupun dosen dengan dosen dapat dilakukan secara virtual. 4.) Pihak yang terlibat: Pihak yang terlibat di sini adalah Pemerintahan, Perguruan Tinggi, Dosen dan Mahasiswa. 5.) Pemecahan masalah: Rumusan masalah metode apa yang digunakan Perguruan Tinggi dalam menghadapi Era Digital Disruptif dan masalah ini dapat dipecahkan dengan menggunakan metode iLearning, yang meliputi 3 (tiga) hal, yaitu : Rinfo, iDu dan iMe.

\subsection{Implementasi}

Dalam menghadapi era digital disruptif, Perguruan Tinggi Raharja mempunyai metodologi pembelajaran yang efektif sesuai dengan era disruptif saat ini.

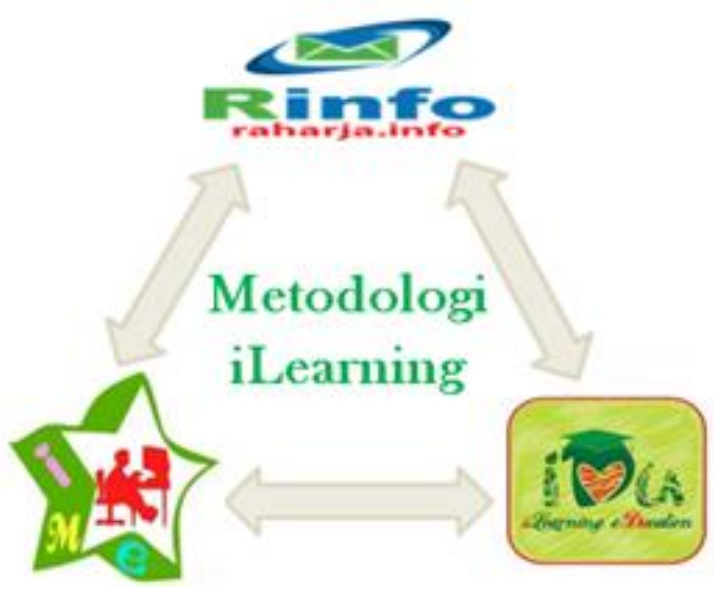

Gambar 6. Metodologi iLearning 
Gambar 6 menjelaskan metodologi pembelajaran yang digunakan Perguruan Tinggi Raharja dalam menghadapi era disruptif. Metodologi ini dinamakan dengan iLearning, yang melibatkan 3 (tiga) hal, yaitu :

1. Rinfo (Email Raharja.info)

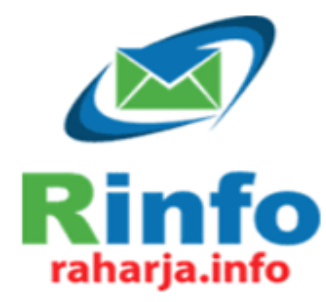

Gambar.7 Logo Rinfo

Rinfo adalah fasilitas komunikasi email yang disediakan oleh Perguruan Tinggi Raharja untuk menunjang terjalin komunikasi antara mahasiswa dengan mahasiswa maupun mahasiswa dengan dosen yang terbentuk di dalam milis group Rinfo.

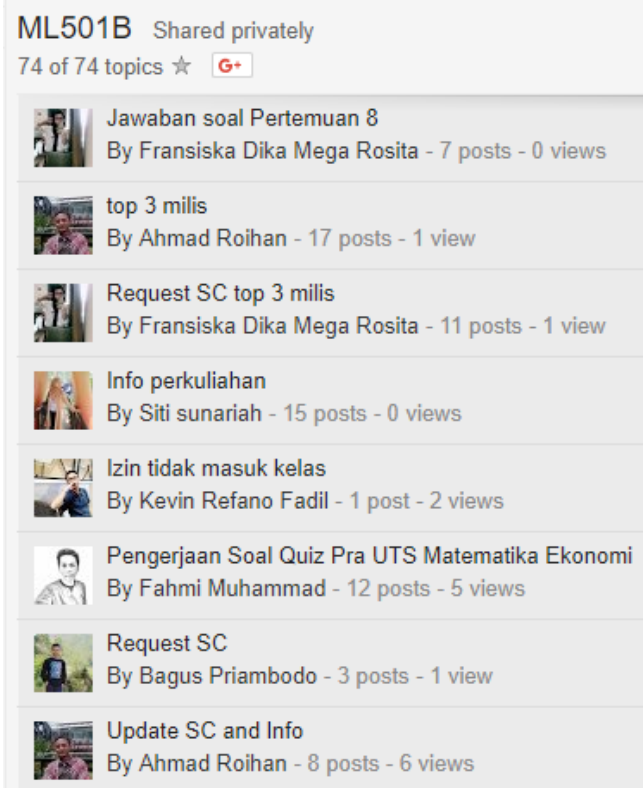

Gambar 8 . Komunikasi mahasiswa pada milis Rinfo

Gambar 8 merupakan kegiatan komunikasi yang dilakukan mahasiswa dengan mahasiswa maupun mahasiswa dengan dosen. Yang diambil contoh dari kelas ML501B (Matematika Ekonomi) yang berjalan kurang lebih selama 3 bulan. Pada gambar tersebut terdapat 74 (tujuh puluh empat) topik yang dibahas. Diantaranya : 1.) Mahasiswa dengan nama Fransiska Dika Mega Rosita memberikan jawaban pada materi pertemuan 8 yang terdapat pada iDu. 2.) Dosen Matematika Ekonomi atas nama Ahmad Roihan memberikan informasi top 3 milis. 


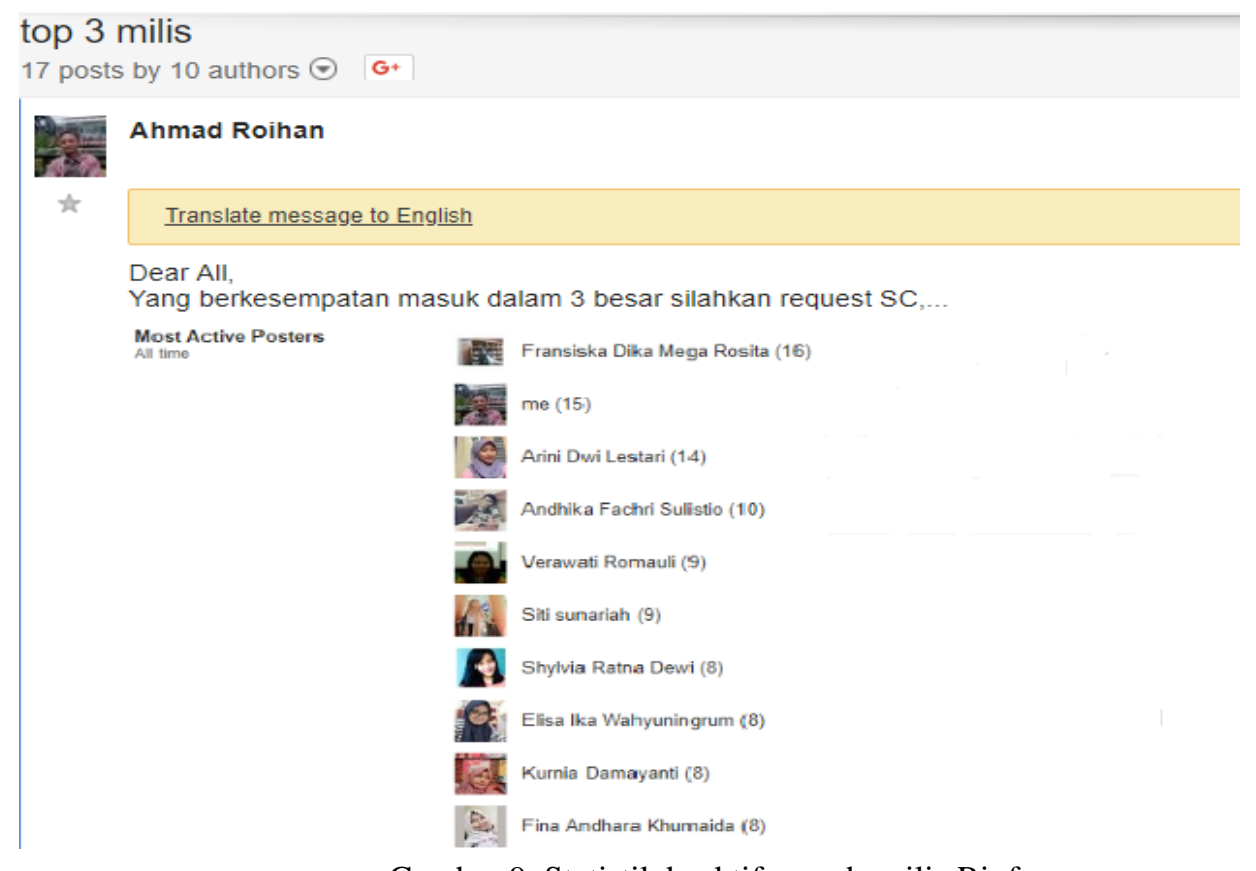

Gambar 9. Statistik keaktifan pada milis Rinfo

Gambar 9 menunjukan statistik mahasiswa dalam keaktifan di milis. Pada gambar tersebut tertera foto profil dan nama user 10 besar yang paling aktif. Angka di dalam kurung menunjukan jumlah postingan yang diposting oleh mahasiswa yang bersangkutan. Dan penilaian yang di terapkan oleh dosen ini, Mahasiswa diharuskan berlomba-lomba dalam menjadi top 3 yang paling aktif akan mendapatkan SC, yaitu point tambahan. Hal ini bertujuan untuk menciptakan suasana kelas yang saling berkompetisi antara mahasiswa satu dengan lainnya dan memotivasi mahasiswa agar aktif selain itu dapat memacu semangat mahasiswa agar lebih unggul dari mahasiswa yang lain.

2. iDu (iLearning Education)

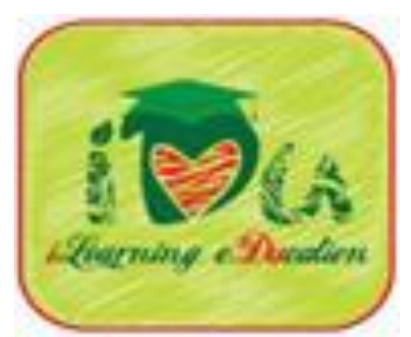

Gambar 10. Logo iDu

iDu adalah media pembelajaran online yang mengkombinasikan tatap muka dan kegiatan belajar online yang difasilitasi oleh Perguruan Tinggi Raharja melalui website idu.raharja.info dengan menggunakan metode Campus Learning Management System iDu. iDu ini berkaitan erat dengan aktivitas kegiatan pembelajaran yang berjalan, karena dalam iLearning segalanya ada didalam sini, mulai dari informasi mengenai KBM, tugas yang diberikan dosen kepada mahasiswa, pengerjaan tugas oleh mahasiswa sampai dengan penilaian yang diberikan dosen terhadap tugas yang telah dikerjakan tersebut. Melalui iDu, mahasiswa dapat dengan mudah mengulang materi pembelajaran dan mengerjakan tugas secara anywhere (dimanapun) dan anytime (kapanpun) tidak terpaku pada jam perkuliahan. 


\section{ML501 Matematika Ekonomi}

\section{All 8 Due Analytics Grading scale}

\begin{tabular}{|c|c|c|c|c|c|c|c|c|}
\hline \multicolumn{2}{|c|}{ Assignment } & \multirow{2}{*}{$\begin{array}{l}\text { Start } \\
\text { Feb } 7 \\
8: 00 \mathrm{gm}\end{array}$} & \multirow{2}{*}{$\begin{array}{l}\text { Due } \\
\text { May } 23 \\
6: 00 \mathrm{pm}\end{array}$} & \multirow{2}{*}{$\begin{array}{l}\% \text { of } \\
\text { overall }\end{array}$} & \multirow{2}{*}{$\begin{array}{c}\text { Submitted } \\
\text { - }\end{array}$} & \multirow{2}{*}{ Graded } & \multirow{2}{*}{$\begin{array}{l}\text { Score } \\
? / 100\end{array}$} & \multirow[t]{2}{*}{ Grade } \\
\hline$>$ & $\begin{array}{l}\text { Special Contribution } \\
\text { (Extra credit) }\end{array}$ & & & & & & & \\
\hline$>$ & $\begin{array}{l}\text { Completeness of SKuP } \\
\text { TM }\end{array}$ & $\begin{array}{l}\text { Feb } 7 \\
8: 00 \mathrm{sm}\end{array}$ & $\begin{array}{l}\text { May } 23 \\
\text { 6:00 pm }\end{array}$ & - & - & & $? / 90$ & \\
\hline$?$ & $\begin{array}{l}\text { Quiz2 } \\
\text { Pertemuan 12·TM }\end{array}$ & $\begin{array}{l}\text { May } 15 \\
5: 10 \mathrm{pm}\end{array}$ & May 15 & - & $\omega$ & & $? / 20$ & \\
\hline$?$ & $\begin{array}{l}\text { UTS } \\
\text { UTS }\end{array}$ & $\begin{array}{l}\text { Mar } 28 \\
5: 00 \mathrm{pm}\end{array}$ & $\begin{array}{l}\text { Mar } 28 \\
6: 30 \mathrm{pm}\end{array}$ & 50 & $\checkmark$ & $\checkmark$ & $\begin{array}{l}84 / 100 \\
84 \%\end{array}$ & $\mathrm{~B}+$ \\
\hline$?$ & $\begin{array}{l}\text { Quiz1 } \\
\text { Pertemuan 7·TM }\end{array}$ & $\begin{array}{l}\text { Mar } 21 \\
5: 10 \mathrm{pm}\end{array}$ & $\begin{array}{l}\text { Mar } 21 \\
5: 40 \mathrm{pm}\end{array}$ & 6.3 & $\checkmark$ & $\checkmark$ & $\begin{array}{c}12 / 20 \\
60 \%\end{array}$ & C \\
\hline$>$ & $\begin{array}{l}\text { Fungsi Linier } \\
\text { Pertemuan } 4 \cdot T M\end{array}$ & $\begin{array}{l}\text { Mar } 2 \\
7: 30 \mathrm{am}\end{array}$ & $\begin{array}{l}\text { Mar } 7 \\
5: 59 \mathrm{pm}\end{array}$ & 6.3 & $\checkmark$ & $\checkmark$ & $\begin{array}{l}20 / 20 \\
100 \%\end{array}$ & $\mathrm{~A}^{+}$ \\
\hline$>$ & $\begin{array}{l}\text { Himpunan \& Sistem Bilangan Nyata } \\
\text { Pertemuan } 2 \cdot \mathrm{TM}\end{array}$ & $\begin{array}{l}\text { Feb } 14 \\
6: 00 \mathrm{pm}\end{array}$ & $\begin{array}{l}\text { Feb } 21 \\
6: 59 \mathrm{pm}\end{array}$ & 6.3 & $\checkmark$ & $\checkmark$ & $\begin{array}{c}13 / 20 \\
65 \%\end{array}$ & $\mathrm{C}+$ \\
\hline$>$ & $\begin{array}{l}\text { 1. Introducing } \\
\text { Pertemuan } 1 \cdot \mathrm{TM}\end{array}$ & $\begin{array}{l}\text { Feb } 7 \\
6: 00 \mathrm{pm}\end{array}$ & $\begin{array}{l}\text { Feb } 17 \\
11: 00 \mathrm{pm}\end{array}$ & 31.3 & $\checkmark$ & $\checkmark$ & $\begin{array}{c}100 / 100 \\
100 \%\end{array}$ & $\mathrm{~A}^{+}$ \\
\hline
\end{tabular}

Gambar 11. Tampilan menu assignments pada iDu

Gambar 11 merupakan tampilan menu assigments pada aplikasi iDu. Pada halaman ini, menampilkan tugas-tugas yang telah dikerjakan oleh mahasiswa. 1.) Assignment : jenis tugas yang diberikan oleh dosen. 2.) Start : waktu diberikan tugas tersebut. 3.) Due : Batas akhir submit tugas. 4.) \% of overall : persentase nilai yang diberikan dosen. 5.) Submitted : Status pengerjaan tugas yang otomatis akan terceklis jika tugas tersebut sudah dikerjakan oleh mahasiswa. 6.) Graded: Status penilaian tugas yang otomatis akan terceklis jika tugas tersebut sudah dinilai oleh dosen.7.) Score : Penilaian yang diberikan dosen terhadap tugas yang dikerjakan oleh mahasiswa. 8.) Grade : dan batas akhir tugas, status dari tugas tersebut apakah sudah dikerjakan dan dicek oleh dosen, serta score dan nilai yang diperoleh. Dengan adanya fitur assignments ini, mahasiswa dapat mengerjakan tugas di tempat yang mereka inginkan dan dosen dapat memantau dan menilai secara langsung tugas yang di kerjakan oleh mahasiswa, tidak terpaku akan metode belajar yang harus bertatap muka dikelas.

3. $\mathrm{iMe}$

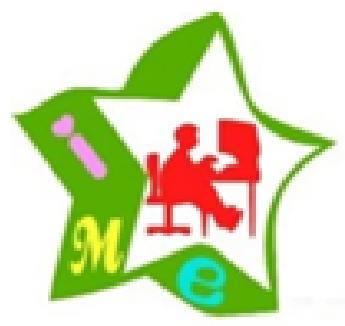

Gambar 12. Logo iMe

iMe merupakan official portal yang ditujukan kepada Pribadi Raharja untuk dipergunakan sebagai media dokumentasi tugas yang diberikan oleh dosen. Yang menarik dalam iMe yaitu, mahasiswa dapat memberikan opini didalam postingan iMe, yang biasa disebut dengan cermi. 
Arini Dwi Lestari on May 3, 2018 at 5:57 am said:

Inovasi VasTmind ini merupakan inovasi yang sangat dahsyat yang Mamoi

cetuskan. Dilihat dari 5 spell ramuan yang masing-masing kata nya memiliki arti yang sangat kuat terlebih lagi disatukan menjadi 5 kekuatan. Yang sangat memberikan energi posifitif bagi yang menerapkannya.

Thanks for Sharing Moi ${ }^{\wedge}$

Reply $\downarrow$

Gambar 13. Testi mahasiswa terhadap iMe

Pada gambar 13 menunjukkan salah satu contoh testimoni mahasiswa yang telah menggunakan dan merasakan manfaat dari iMe. Hal ini juga merupakan salah satu keunggulan dan fasilitas dari iMe, dimana dapat digunakan mahasiswa untuk berkomentar, mengemukakan atau menyampaikan pendapat atas inovasi yang telah dituangkan oleh dosen atau mahasiswa lainnya yang dapat membuat mahasiswa tersebut dapat berfikir kritis, tidak menelan secara mentah-mentah atas informasi yang didapatkan. Selain itu sebagai sarana mahasiswa untuk saling bertukar pendapat agar menciptakan ide yang lebih dahsyat.

Dari 3 langkah metodologi iLearning diatas, mahasiswa mengerjakan tugas dengan cara submit link ime pada iDu, begitupun para dosen memberikan nilai mahasiswa menggunakan iDu pula.

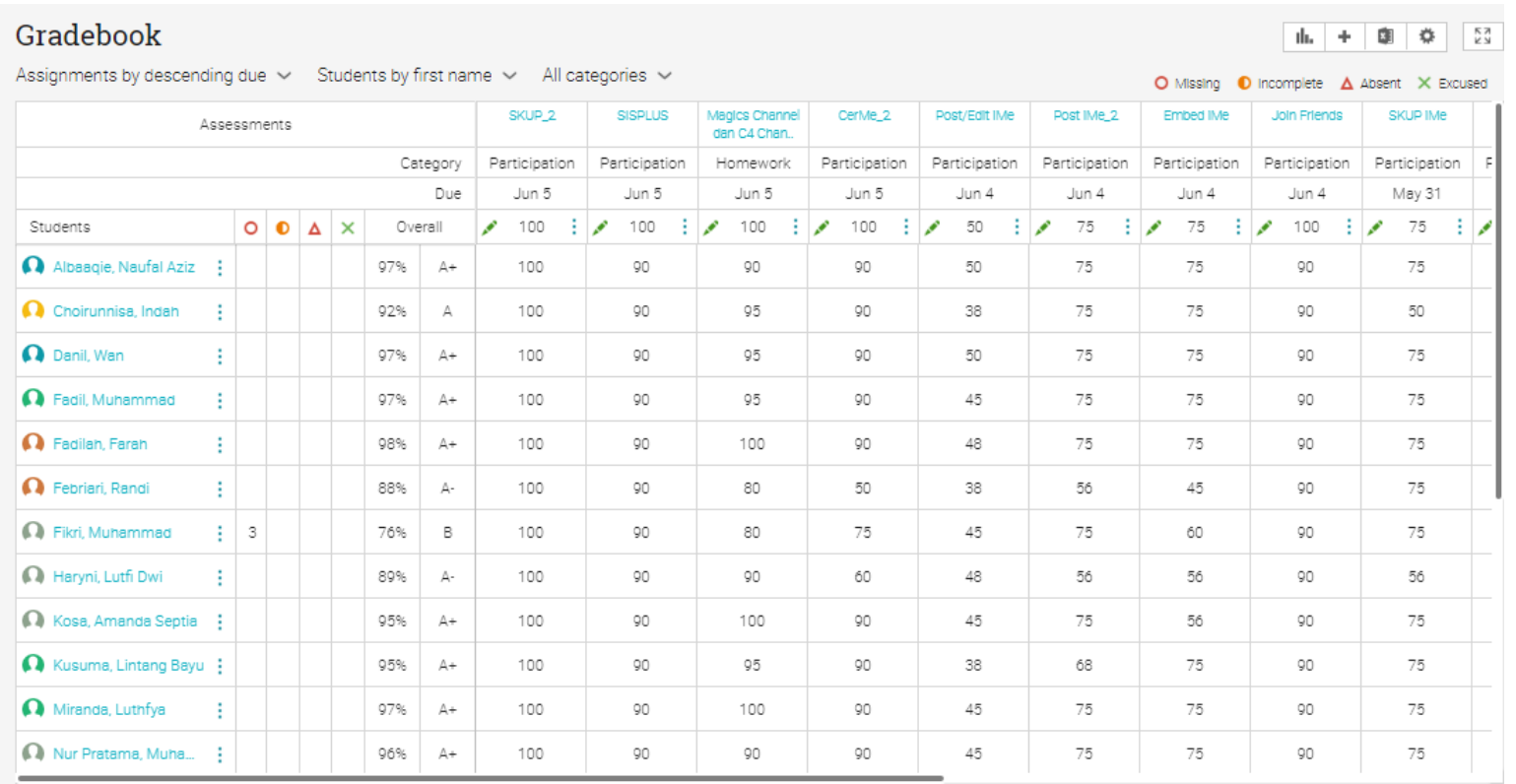

Gambar 14. Penilaian dosen menggunakan iDu

Gambar 14. Merupakan interface apabila dosen hendak memberikan nilai kepada mahasiswa yang telah mengerjakan tugas yang diberikan. Didalam gradebook ini tertera shorting berupa abjad nama mahasiswa maupun nilai yang didapatkan mahasiswa. Setelah dosen memberikan nilai, maka nilai itu akan otomatis tampil pada assignment mahasiswa, untuk lebih jelasnya tertera pada gambar 11 . 


\section{PENUTUP}

A. Kesimpulan

Dengan metode ini, kegiatan belajar mengikuti pola modern yang memberikan kemudahan berupa modul digital yang dapat diakses di iDu, penguasaan materi dan kualitas pembelajaran dapat ditingkatkan serta keaktifan mahasiswa yang dapat dikalkulasi di dalam Group Milis Rinfo. Pola pikir mahasiswa akan menjadi lebih kreatif, inovatif, dan kritis dengan adanya iMe sebagai wadah mahasiswa dalam menuangkan inspirasi dan aspirasi. Selain itu, memberikan perubahan yang signifikan dalam proses pembelajaran, dengan difasilitasi iPad dapat membuat mahasiswa memiliki ketertarikan dalam belajar. Sehingga akan terjalin interaksi yang baik antara dosen dengan mahasiswa selain itu akan mudah untuk menghidupkan pembelajaran yang efektif dan efisien di dalam kelas.

B. Saran

Untuk mengembangkan lebih dalam mengenai penelitian ini, penulis menyarankan untuk mengembangkan 2 grafik pada iDu, yaitu : grafik seberapa banyak mahasiswa mengerjakan tugas yang diberikan dan grafik penilaian mahasiswa.

\section{DAFTAR RUJUKAN}

Aini, Q., Graha, Y. I., \& Zuliana, S. R. (2017). Penerapan Absensi QRCode Mahasiswa Bimbingan Belajar pada Website berbasis YII Framework. Sisfotenika, 7(2), 207-218.

Aini, Q. (2016). Pengembangan PEN+(Penilaian Plus) Untuk Efisiensi RPU Dalam Rangka Meningkatkan Tingkat Kepuasan. STMIK Raharja Tangerang.

Aisyah, E. S. N., Maimunah, M., \& Martono, A. (2017). Effectiveness of Book Closing Using Web Based Accounting Online System 2.0 to Know the Company's Financial Ratios. Aptisi Transactions of Management (ATM), 1(1), 60-65.

Baharudin, A. F., Sahabudin, N. A., \& Kamaludin, A. (2017). Behavioral Tracking in E-Learning by Using Learning Styles Approach. Indonesian Journal of Electrical Engineering and Computer Science, $8(1), 17-26$.

Comiskey, D., \& MCCARTAN, K. (2013).From eLearning to iLearning. Reviewing the Extent to which 3D Printing May Offer an Accessible, Ubiquitous and Affordable Technical Design Tool for Architectural Technology Undergraduates and Practice?. $70,105$.

Hamdu, G., \& Agustina, L. (2011). Pengaruh motivasi belajar siswa terhadap prestasi belajar IPA di sekolah dasar. Jurnal penelitian pendidikan, 12(1), 90-96

Hamid, E. S. Disruptive Innovation: Manfaat Dan Kekurangan Dalam Konteks Pembangunan Ekonomi.

Indrianti, R., \& Hadi, C. (2012). Hubungan antara modal psikologis dengan keterikatan kerja pada perawat di instalasi rawat inap rumah sakit jiwa menur Surabaya. Jurnal psikologi industri dan organisasi, 1(2), 110-115.

Kenney, M., Rouvinen, P., \& Zysman, J. (2015). The digital disruption and its societal impacts. Journal of Industry, Competition and Trade, 15(1), 1-4.

Kurniawan, R., \& Henderi, F. N. (2012). Penggunaan iPad Mendukung Pembelajaran pada Mahasiswa iLearning. Online]. Tersedia di http://www. academia. edu.

Molla, A., Cooper, V., \& Karpathiou, V. (2016). IT Managers' Perception and Response to Digital Disruption: An Exploratory Study. arXiv preprint arXiv:1606.03534.

Nasriyah, R., Arham, Z., \& Aini, Q. (2016). Profile matching and competency based human resources management approaches for employee placement decision support system (case study). Asian J. Appl. Sci, 9(2), 75-86.

Oey-Gardiner, EM., Susanto I dan Amin A.2017. Era Disrupsi:Peluang dan tantangan Pendidikan Tinggi Indonesia.

Paulus, E., Suryani, M., Farabi, R., Yulita, I. N., \& Pradana, A. (2016). EVALUASI APLIKASI SEMIIMMERSIVE VIRTUAL REALITY PADA BIDANG PENDIDIKAN MENURUT ASPEK HEURISTIK DAN PEMBELAJARAN. JIKO (Jurnal Informatika dan Komputer), 1(2).

Rahardja, U., Aini, Q., \& Faradilla, F. (2018). Implementasi Viewboard Berbasis Interaktif Javascript Charts Pada Sistem Penilaian Perkuliahan. Jurnal Ilmiah Teknologi Informasi Asia, 12(2), 91-102.

Rahardja, U., Aini, Q., \& Khoirunisa, A. (2017). Implementasi Business Intelligence Menggunakan Highchart pada Sistem Penilaian Absensi berbasis YII Framework. CSRID (Computer Science Research and Its Development Journal), 9(2), 115-124.

Rahardja, U., Lutfiani, N., \& Alpansuri, M. S. (2018). Pemanfaatan Google Formulir Sebagai Sistem 
Pendaftaran Anggota Pada Website Aptisi. or. id. SISFOTENIKA, 8(2), 128-139.

Rahardja, U., \& Nurdin, I. (2014). Implementasi iMe (iLearning Media) Dalam Mendukung Sistem Pembelajaran iLearning Pada Perguruan Tinggi. CCIT Journal, 8(1), 167-182.

Rahardja, U., Tiara, K., \& Rosalinda, I. A. (2016). Pemanfaatan Google Scholar Dan Citation Dalam Memenuhi Kebutuhan Pembuatan Skripsi Mahasiswa Pada Perguruan Tinggi. Technomedia Journal, $1(1), 95-113$

Rasdiana, E., Muhamad, F. N., \& Kurniaji, R. (2016). PEMANFAATAN RINFO FORM SEBAGA MEDIA PEMBUATAN KUESIONER DALAM PROSES PENGUMPULAN DATA PADA PERGURUAN TINGGI. Technomedia Journal, 1(1), 78-94.

Rossing, J. P., Miller, W. M., Cecil, A. K., \& Stamper, S. E (2012). iLearning: The future of higher education? Student perceptions on learning with mobile tablets. Journal of the Scholarship of Teaching and Learning, 12(2), 1-26.

Silaban, R., \& Napitupulu, M. A. (2012). Pengaruh media mind mapping terhadap kreativitas dan hasil belajar kimia siswa SMA pada pembelajaran menggunakan advance organizer.

Simatupang, N. (2005). Bermain sebagai upaya dini menanamkan aspek sosial bagi siswa sekolah dasar. Jurnal Pendidikan Jasmani Indonesia, 3(1)

Sunarya, A., Rafika, A. S., \& Rahayu, S. (2017). Analyze and Record a series of Purchase Transactions on Companies using Online Accounting Software. Aptisi Transactions of Management (ATM), 1(1), 4247.

Supriati, R., Aryani, D., \& Maesaroh, S. (2017). Asset Management Using a Web-Based Accounting Online System To Maintain Value of Company Assets. Aptisi Transactions of Management (ATM), 1(1), 3441.

Tedjasaputra, M. S. (2001). Bermain, mainan dan permainan. Grasindo.

Utesheva, A., Simpson, J. R., \& Cecez-Kecmanovic, D. (2016). Identity metamorphoses in digital disruption: a relational theory of identity. European Journal of Information Systems, 25(4), 344-363.

Wahyudi, A. B. E., \& Suardiman, S. P. (2013). Meningkatkan karakter dan hasil belajar IPS menggunakan metode bermain peran pada siswa SD. Jurnal Prima Edukasia, 1(2), 113-123.

Wang, M., Hauze, S., Olmstead, W., Aziz, B., Zaineb, B., \& Ng, J. (2014, December). An exploration of intelligent learning (iLearning) systems. In Teaching, Assessment and Learning (TALE), 2014 International Conference on (pp. 327-332). IEEE. 